\title{
A Review of Secret Key Distribution Based on Bounded Observability
}

\author{
Jun Muramatsu
}

\begin{abstract}
Secret key distribution is a technique for a sender and a receiver to share a secret key, which is not known by any eavesdropper, when they share no common secret information in advance. By using this technique, the sender and the receiver can transmit a message securely in the sense that the message remains secret from any eavesdropper. We introduced a secret key distribution based on the Bounded Observability (Muramatsu et al. 2010, 2013, 2015), which provides a necessary and sufficient condition for the possibility of secret key distribution. This condition describes limits on the information obtained by observation of a random object, and models the practical difficulty of completely observing random physical phenomena.
\end{abstract}

Keywords Secret key distribution · Information-theoretic security • Secret key agreement $\cdot$ Bounded observability

\section{References}

J. Muramatsu, K. Yoshimura, P. Davis, Information theoretic security based on bounded observability, in Information Theoretic Security, vol. 5973. Lecture Notes on Computer Science. (Springer, Berlin, 2010), pp. 128-139

J. Muramatsu, K. Yoshimura, P. Davis, A. Uchida, T. Harayama, Bounded Observability ni motoduku himitu-kagi-haisou (in Japanese). Bull. Jpn Soc. Ind. Appl. Math. (Ouyou-suuri) 23(1), 11-20 (2013)

J. Muramatsu, K. Yoshimura, P. Davis, A. Uchida, T. Harayama, Secure key distribution based on bounded observability. Proc. IEEE 103(10), 1762-1780 (2015)

J. Muramatsu ( $\square)$

NTT Communication Science Laboratories, NTT Corporation, 2-4, Seika-cho,

Soraku-gun, Hikaridai, Kyoto 619-0237, Japan

e-mail: jun.muramatsu@ieee.org

(C) The Author(s) 2021

T. Takagi et al. (eds.), International Symposium on Mathematics,

Quantum Theory, and Cryptography, Mathematics for Industry 33,

https://doi.org/10.1007/978-981-15-5191-8_5 
Open Access This chapter is licensed under the terms of the Creative Commons Attribution 4.0 International License (http://creativecommons.org/licenses/by/4.0/), which permits use, sharing, adaptation, distribution and reproduction in any medium or format, as long as you give appropriate credit to the original author(s) and the source, provide a link to the Creative Commons license and indicate if changes were made.

The images or other third party material in this chapter are included in the chapter's Creative Commons license, unless indicated otherwise in a credit line to the material. If material is not included in the chapter's Creative Commons license and your intended use is not permitted by statutory regulation or exceeds the permitted use, you will need to obtain permission directly from the copyright holder.

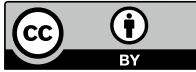

